\title{
Research on the WeChat Information Transmission Topology Based on Social Network Analysis
}

\author{
Wang Kun* and Sun Duoyong
}

College of Information System and Management, National University of Defense Technology, Changsha, Hunan, 410073, P.R. China

\begin{abstract}
With the rapid development of mobile internet technology, Social Media has become an important way for us to communicate with others. Meanwhile, Social Media is regarded as the most popular information exchange and knowledge-sharing platform by more and more people, making its network structure and information transmission topology attract wide attention. WeChat is one of the most commonly used Social Media in China, which was developed by Tencent in 2011. As the number of WeChat customers is very huge, traditional analytical methods have become nonapplicable. In this paper, we tried to use Social Network Analysis (SNA), which is capable of handling huge data, to reveal the relationship networks of WeChat. On this basis, we chose a WeChat user randomly and listed groups that he participated in. Through analyzing its network architecture and data indicators, we found out three main information transmission topologies of WeChat.
\end{abstract}

Keywords: Information transmission topology, Social network analysis, WeChat, Social media, Network density, UCINET.

\section{INTRODUCTION}

With the popularization of network and development of mobile internet technology, people have entered into a new era which is more open and more sharing. Communication between people has broken the limitations of space and time and being no longer confined to the real world, more and more information exchange occurs in the Social Media. With the network community features becoming gradually powerful, Social Media has become a powerful medium, having a strong impact on the traditional platform. As a new transmission method, Social Media not only imposes personal privacy, but also stresses on publishing public information in a customized private space. While it is an extension of the real world, Social Media occupies a very important position in the future social development.

WeChat is one of the most famous Social Media in China, which occupies a considerable market share in the similar applications, such as MiTalk, momo, etc. (Fig. 1). WeChat provides several services such as Mobile Text, Voice Messaging, Group Chat, Moments, and Location Sharing. It started providing Web-based client, with messaging and file transfer functions, in 2012. This means that it is possible to join into the WeChat network by your computer without a Smartphone. According to Xinhua, the total number of WeChat users reached about 355 million, in October 2013, with approximately thirty percent being abroad [1]. In addition, Combined Monthly active users of the Weixin and WeChat increased by $57 \%$ over a year to 438 million at the end of the second quarter of 2014 [2].

*Address correspondence to this author at the College of Information System and Management, National University of Defense Technology, Changsha, Hunan, 410073, P.R. China; E-mail: quinone@163.com

1874-110X/15

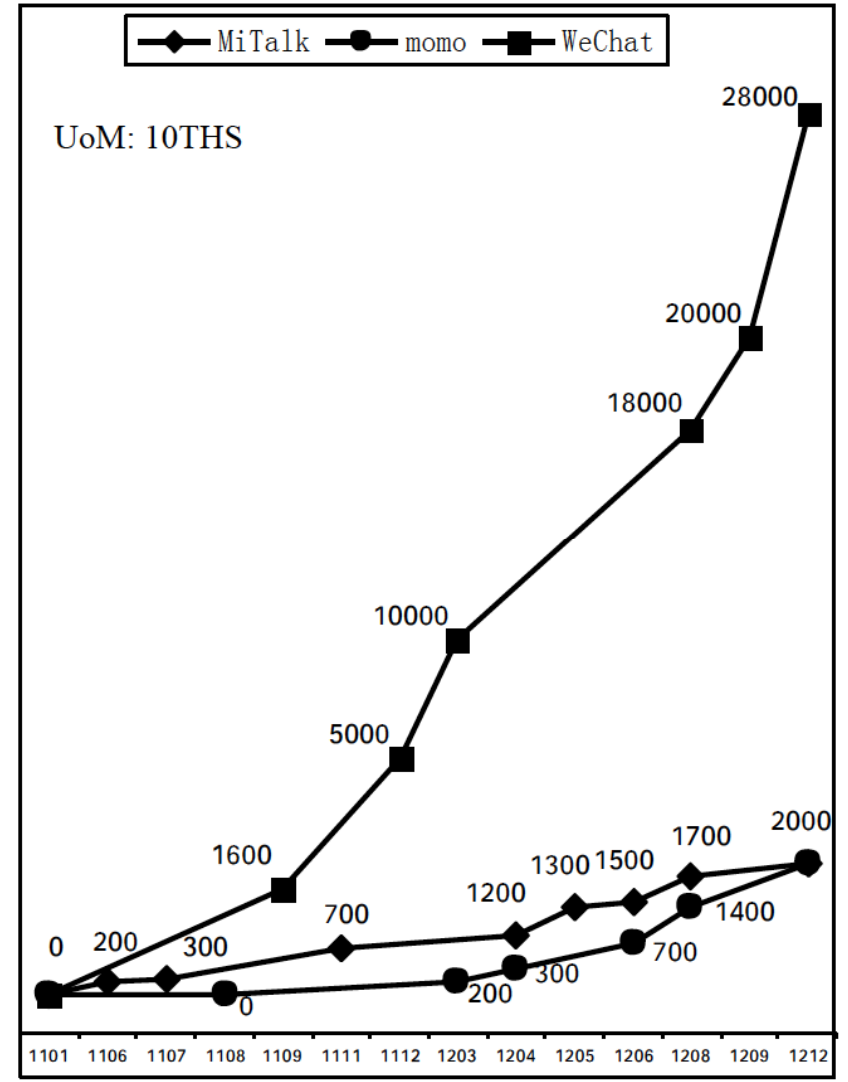

Fig. (1). Active users of the three mainstream Social Media in the last 2 years [3].

Although the growth rate fluctuates up and down every month, the number of WeChat active users is still increasing rapidly (Fig. 2). 
Number of Users $\longrightarrow$ Growth rates

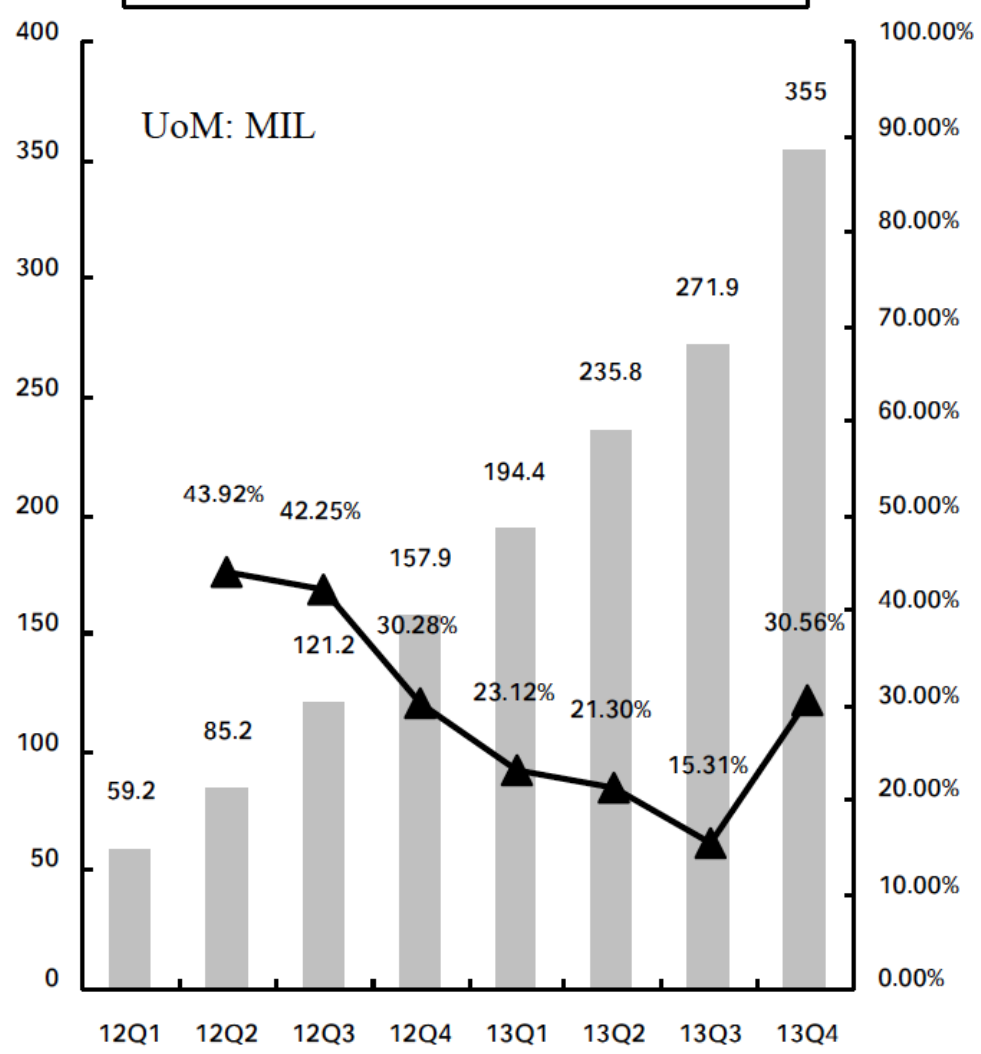

Fig. (2). Active users of Wechat in last 2 years [4].

In social sciences, the structural research methods based on information interaction between society actors are called Social Network Analysis (SNA). SNA is used to study individuals and their relationships. It seeks to reveal patterns of the relationships, and tries to obtain the network structure, functions and content of the groups, as well as the status of individuals in the groups. Due to its complex structure, this research decided to use the methods of Social Network Analysis to study the information transmission topology of WeChat.

\section{THE MAIN MEASURES OF SOCIAL NETWORK ANALYSIS}

Social networks research appeared early in 1934. Moreno, who was a famous American social psychologist, began to study small groups with the method of Morphometry. Another few scholars thought that Social network Analysis originated from the theory of Anthropology in England, because Radcliffe Brown was the first person who proposed the concept of social network. J.A. Barnes, D. Cartwright, T.M. Ncomb, and A. Bavelas are the representatives who performed their research on Social networks quite early [5, 6].

Social network refers to the collections between social actors and their relationships, and it is composed of multiple points (social actors) and connections between the points (the relationship between actors) [7]. Before the Internet appeared, SNA was only used to study the real society groups. In recent years, SNA has begun to research groups who exist in the virtual space. The functions of SNA are finding features of individuals and small groups from the whole network analysis. Node and relationship are the basis of SNA theories, models and applications.

Centrality degree is the most commonly used indicator to measure the network properties, which is also the basis of SNA. In the recent years, several scholars have been trying to innovate this concept in order to consummate the index system of SNA. Dr. Nasrullah Memon has proposed a series of conceptions such as Network Efficiency, Dependency Centrality and Location Role Centrality [8]. This paper is based on studying the network of a randomly chosen WeChat customer aiming to obtain the information transmission topology based on the SNA. Here, mainly the characteristics of "Density", "Centrality" and "Cohesive Subgroup" are studied. A brief introduction about these indicators is presented at the very beginning [9].

\subsection{Network Density}

This is the most commonly used research index in SNA. In networks, a point may be (in addition to itself) connected to any other point. Network Density is mainly used to describe how closely the links are between the nodes in the graph. This indicator is most dependent on the inclusiveness and nodal degree of the networks. In the undirected network having $\mathrm{n}$ points, the connection from point $\mathrm{A}$ to point $\mathrm{B}$ is a line, which is most likely to have $\mathrm{n}(\mathrm{n}-1) / 2$ different pieces (1). In the directed network, the data matrix is asymmetric, and the line from point A to point B does not necessarily 
contain the one from point B to point A. Therefore, the maximum number of connections might have exactly equal points, that is $n(n-1)$, and the calculation formula of the directed network may become a bit different to that in the undirected network (2).

$$
\begin{aligned}
& D_{u}=\frac{1}{n(n-1) / 2} \\
& D_{d}=\frac{1}{n(n-1)}
\end{aligned}
$$

\subsection{Point Centrality}

Point Centrality is used to describe the importance of position with a point in the entire network. This concept is derived from the Sociometrics. A. Bavelas verified the following assumptions that once the relationship is established, if one point has a direct link with almost every point in the network, then this point is on the center position, which would hold greater rights in this network [10], when he firstly got his groundbreaking research on Point Centrality (Freeman, 1979:215). Point Centrality can be measured by the number of points having direct contact with this point in the network. In directed network, always two indicators exist which are called in-centrality and out-centrality. The unified formula is as follows (3):

$$
C_{R D}=\frac{x_{i}+x_{o}}{2(n-1)}
$$

\subsection{Betweenness Centrality}

According to the historical experience, if a point is on many shortcuts of other points (shortest path), this actor occupies an important position, because it holds such position that can affect the group by controlling the proceeding of the information transmission. According to the concept of "Structural Hole", Burt put forward a situation that relationship of point $A$ and point $B$ relies on point $C$, if the links between them cross the other points [11]. Betweenness Centrality measures the degree of how a certain node could control the information transmission channel in the network, which is as follows (4) (5):

$$
\begin{aligned}
C_{A B i} & =\sum_{j}^{n} \sum_{k}^{n} g_{j k}(\mathrm{i}) / g_{j k},(\mathrm{j}<\mathrm{k}, \mathrm{j} \neq \mathrm{k} \neq \mathrm{i}) \\
C_{R B i} & =\frac{2 C_{A B i}}{n^{2}-3 n+2}
\end{aligned}
$$

\subsection{Closeness Centrality}

Closeness Centrality is an indicator which shows how a point can avoid others' control in a network. A. Bavelas, G. Sabidussi and other scholars defined Closeness Centrality according to the measure "distance" between these points (Friedman, 1979). The quantification definition is to calculate sum of distances between a point and all the other points in the whole network. If the "distance" is very short, such point is "closer" to the other ones. Its influence on information resources, power, prestige and other aspects would become higher. In order to facilitate the comparing of Closeness Centrality in different kind of networks, we often put the sum of distances divided by (n-1), then the indicator becomes standardized; its expression is as follows (6):

$C_{R P i}^{-1}=\frac{\sum_{j=1}^{n} d_{i j}}{(n-1)}$

\subsection{Clustering Analysis}

Clustering Analysis starts from the members in social network and relationships between them [12]. Social Structure is used to describe relationship mode among social actors, no matter whether they really exist or are underlying (Wellman and Berkowitz, 1988; Berkowitz, 1983; Scott, 2000). The concept of cohesion subgroup includes the NCliques (Scott, 2000; Wasserman and Faust, 1994), N-Clan (Alba and R. J. Mokken, 1973), K-Plex (Seidman and Foster), K-Core, and Lambda Set (Borgatti, Everett and Shirey, 1990). When connections between some members of a network are much closer, these points are classified as the cohesion subgroup. The contents, in which Clustering Analysis needs to be explained, are how many cohesion subgroups exist, and how to explain the relationship between members of a sub-group. The relationships of actors in same cohesion subgroup are more frequent, direct, and active, and we could find this conclusion through many different ways [13].

\section{RELATED WORKS}

Information transmission topology is a description regarding network structure and is also a problem-solving approach in some ways and layers. Since the establishment of Social Communication, researchers have started to pay much attention on the study of information dissemination mode, and have proposed hundreds of models. Traditional models help us to understand network itself and general principles more fully. In the previous studies, models were built on the basis of sociological research, and put much more emphasis on the social propagation. The information transmission topology can be divided into three cases: the Linear Model, the Feedback Model and the Social System Model [14].

In the Linear Model, the most obvious flaw is that the process of information transmission in human society is described as the one-way flow line, ignoring the feedback factors and other social factors. The Feedback Model reflects the reality of this proceeding more objectively and accurately, but it still has not provided a clear description of relationship between the information transmission and society (Fig. 3). The Social System Model is recognized to be a huge leap in this area. Researchers have paid more attention on the problems and conditions in the process, and have explicitly placed it among the general community research (Fig. 4).

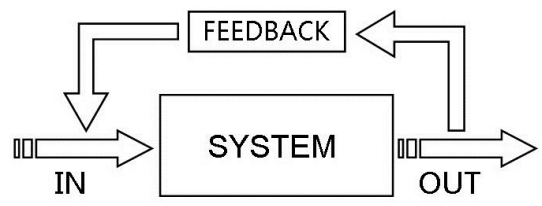

Fig. (3). Example of the feedback model. 


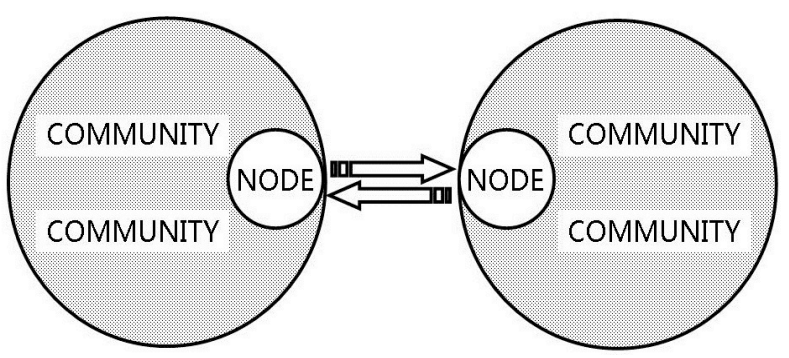

Fig. (4). Example of the social system model.

Small-world network is one of the most important basic theories in complex network theory. It can be traced back to the earliest Konigsberg Seven Bridges Problem. Euler, one of the most famous international mathematicians in 18 century, used the method of Graph Theory for solving the historic challenge [15]. The two landmark papers, "Collective dynamics of 'small-world' networks" and "Emergence of scaling in random networks", were published by Prof. Watts and Prof. Barabasi respectively at the end of the last century. Moreover, these two distinguished papers have led directly to the huge changes in scientific exploration of Complex Network Science [16].

The Six Degrees of Separation, which was proposed by the famous American Social Psychologist Milgram, pointed out that the "weak link" is very prevalent in our society. The theory indicates that each individual is six or fewer steps away from any other individual in this world, so a chain of "friend to friend" can establish links or transmit information among any two persons in a maximum of six steps. This experiment was originally designed and implemented by Frigyes Karinthy, in 1929 [17]. Professor Watts and his team tried to recreate Milgram's famous experiment through the Internet in 2001, when he was teaching at Columbia University. They set up a program that invited about 48,000 senders randomly and requested them to deliver an e-mail message to 19 certain targets. The participants came from 157 different countries all over the world. The results show that the average number of intermediaries was around 6 [18]. Recently, Karl Bunyan has released an interesting application which can calculate the degrees of separation among different users in the Facebook. We call it "Six Degrees". Its calculation shows that the maximum degree of separation is 12 , whereas the average one is only 5.73 [19].

Based on these theories above, it can be observed that Social Media is usually expressed as the grouping of individuals into specific groups, just like the urban communities or neighborhood subdivision in country. Such as a study of 5.2 billion Twitter users with these kinds of relationships has shown that the average distance is only 4.67. According to the statistics, almost everyone on Twitter is less than 6 steps away from each other, while about half of them are only 4 steps away [20]. The networks are full-filled with millions of individuals who are trying to meet others, to share the firsthand information or pictures of cooking, gardening, sports, and even finding employment, interest groups and so on. The topics are as varied and rich as the story of our universe [21].

With the emergence of Social Media, especially after the popularization of the Wireless Networking, the exchange of information has become more and more frequent in the virtual network space. It has also opened up new areas for studying information transmission topology. Although the product of traditional research is similar to the reality community, the classic model of Social Media is still different. As Wechat is a typical social media, original methods have become unsuitable; therefore, in order to analyze the topology and behavior of such groups, it is necessary to use methods from social network analysis [22]. By modeling the individuals and groups we face in a network, we can measure many kinds of important properties in this network through the visualization methods, especially information transmission topology discussed in this paper.

\section{ANALYSIS OF WECHAT USER'S DATA BASED ON UCINET}

A WeChat user was chosen randomly, and the groups that he joined were listed as the basic data. The first step was to establish the user's analysis matrix, and then a comprehensive study was conducted on this network. This mainly included Centrality and Clustering Analysis. Centrality analysis involves revealing the prominent one with high activity in the network, which is significant for impact of the entire organization. Clustering is used to find the similar partners. According to theory of SNA, they may exhibit similar behaviors in the real world.

UCINET is a kind of software which can help simplify the quantitative analysis of social networks. It can format the data from a directed or undirected network into an adjacency matrix, and describe the features of a network by numerical and visual representation. It also contains capability to utilize some relational databases and reveals features of this kind of network [23].

Based on the data of the randomly chosen WeChat user [24], and according to the conversion formula: $\mathrm{S}=\mathrm{AA}^{\mathrm{T}}$, the Affiliation Matrix (Table 1) and the Adjacency Matrix (Table 2) can be obtained.

\subsection{Centrality Analysis}

Network and its node have many characteristics, such as density, centrality and so on. The node's centrality degree mainly includes Point Centrality, Betweenness Centrality, and Closeness Centrality. As the Centralities above are particularly dependent on the initial distance among the nodes, we have every reason to believe that there are obvious differences between the globally central and locally central networks. In order to solve this problem, Prof. Banacich proposed a new concept in 1987, which was called "Banacich Power". In response to suspicions of a few other scholars (Knoke and Burt, 1983), Prof. Banacich promoted his own research and the latest achievement was the general measurement formula (7):

$$
C_{i}=\sum_{j} r_{i j}\left(\alpha+\beta c_{j}\right)
$$

After the calculation of UCINET, all the abovementioned indicators are shown in Tables 3 and 4. Due to the differences between the Graph Centrality and Centralization of a Graph, this paper is focused on the former one. In order to facilitate the following analysis, most of the data were substantially taken as normalized. 
Table 1. The affiliation matrix of the WeChat user.

\begin{tabular}{|c|c|c|c|c|c|c|}
\hline & G1 & G2 & G3 & G4 & G6 \\
\hline \hline WK & 1 & 1 & 1 & 1 & 1 \\
\hline LB & 1 & 0 & 0 & 1 & 0 & 0 \\
\hline LZ & 1 & 1 & 0 & 1 & 1 \\
\hline QXY & 0 & 0 & 0 & 1 & 0 \\
\hline LZH & 1 & 0 & 0 & 0 & 0 \\
\hline TM & 1 & 0 & 0 & 1 & 0 \\
\hline YB & 0 & 0 & 0 & 0 \\
\hline GN & 0 & 0 & 0 \\
\hline
\end{tabular}

Table 2. The adjacency matrix of the WeChat user.

\begin{tabular}{|c|c|c|c|c|c|c|c|c|}
\hline & WK & LB & $\mathbf{L Z}$ & QXY & LZH & TM & YB & GN \\
\hline WK & 6 & 3 & 4 & 2 & 2 & 2 & 1 & 1 \\
\hline LB & 3 & 3 & 3 & 0 & 2 & 2 & 0 & 1 \\
\hline LZ & 4 & 3 & 4 & 0 & 2 & 2 & 0 & 1 \\
\hline LZH & 2 & 2 & 2 & 0 & 2 & 2 & 0 & 1 \\
\hline $\mathrm{TM}$ & 2 & 2 & 2 & 0 & 2 & 2 & 0 & 1 \\
\hline YB & 1 & 0 & 0 & 1 & 0 & 0 & 1 & 0 \\
\hline
\end{tabular}

Table 3. The user's centrality analysis degree.

(3-1)

\begin{tabular}{|c|c|c|c|c|}
\hline & Degree Centrality & NrmDegree Centrality & Share Centrality & NrmBonacich Power \\
\hline \hline WK & 15.000 & 53.571 & 0.227 & 3.568 \\
\hline LZ & 12.000 & 42.857 & 0.182 & 3.655 \\
\hline LB & 11.000 & 39.286 & 0.167 & 2.741 \\
\hline TM & 9.000 & 32.143 & 0.136 & 2.741 \\
\hline LZH & 9.000 & 32.143 & 0.076 & 1.523 \\
\hline GN & 5.000 & 17.857 & 0.045 & 0.914 \\
\hline QXY & 3.000 & 10.714 & 0.030 & 0.609 \\
\hline YB & 2.000 & 0.030 & & \\
\hline
\end{tabular}


(3-2)

\begin{tabular}{|c|c|c|c|c|}
\hline & FlowBet Centrality & nFlowBet Centrality & PrBet Centrality & EgoBet Centrality \\
\hline \hline WK & 25.368 & 60.399 & 28.000 & 10.000 \\
\hline LZ & 4.368 & 10.399 & 6.000 & 0.000 \\
\hline LB & 4.322 & 10.291 & 6.000 & 0.000 \\
\hline TM & 3.994 & 9.509 & 6.000 & 0.000 \\
\hline LZH & 3.994 & 9.509 & 6.000 & 0.000 \\
\hline GN & 2.086 & 4.966 & 6.000 & 0.000 \\
\hline QXY & 6.000 & 14.286 & 3.000 & 0.000 \\
\hline YB & 4.000 & 9.524 & 3.000 & 0.000 \\
\hline
\end{tabular}

(3-3)

\begin{tabular}{|c|c|c|c|c|}
\hline & Closeness Centrality & Farness Centrality & Reach-Based Centrality & NormdwRea Centrality \\
\hline \hline WK & 100.000 & 7.000 & 8.000 & 1.000 \\
\hline LZ & 77.778 & 9.000 & 7.000 & 0.875 \\
\hline LB & 77.778 & 9.000 & 7.000 & 0.875 \\
\hline TM & 77.778 & 9.000 & 7.000 & 0.875 \\
\hline LZH & 77.778 & 9.000 & 7.000 & 0.875 \\
\hline GN & 77.778 & 9.000 & 7.000 & 0.875 \\
\hline QXY & 58.333 & 12.000 & 5.500 & 0.688 \\
\hline YB & 58.333 & 12.000 & 5.500 & 0.688 \\
\hline
\end{tabular}

Table 4. Results of structural hole measures.

(4-1)

\begin{tabular}{|c|c|c|c|c|}
\hline & EffSize Measures & Efficie Measures & Hierarc Measures & Indirec Measures \\
\hline \hline WK & 4.067 & 0.581 & 0.155 & 0.511 \\
\hline LZ & 1.542 & 0.308 & 0.104 & 0.730 \\
\hline LB & 1.591 & 0.318 & 0.094 & 0.765 \\
\hline TM & 1.704 & 0.341 & 0.061 & 0.814 \\
\hline LZH & 1.704 & 0.341 & 0.061 & 0.904 \\
\hline GN & 1.633 & 0.327 & 0.007 & 0.110 \\
\hline QXY & 1.167 & 0.583 & 0.000 & 0.667 \\
\hline YB & 1.000 & 0.500 & \\
\hline
\end{tabular}




\begin{tabular}{|c|c|c|c|c|}
\hline & Degree Measures & Density Measures & Constra Measures & Ln(Cons Measures \\
\hline \hline WK & 7.000 & 1.179 & 0.386 & -0.951 \\
\hline LZ & 5.000 & 1.700 & 0.658 & -0.419 \\
\hline LB & 5.000 & 1.800 & 0.679 & -0.387 \\
\hline TM & 5.000 & 2.000 & 0.697 & -0.361 \\
\hline LZH & 5.000 & 2.000 & 0.697 & -0.316 \\
\hline GN & 5.000 & 2.400 & 1.003 & 0.003 \\
\hline QXY & 2.000 & 1.000 & 1.389 & 0.329 \\
\hline YB & 2.000 & 2.000 & & \\
\hline
\end{tabular}

Table 5. Results of cohesive subgroup analysis.

(5-1)

\begin{tabular}{|c|c|}
\hline Level & Users (Concor) \\
\hline \hline 1 & WK, LB, LZ, GN, LZH, TM; YB, QXY \\
\hline 2 & WK; LB, LZ, TM, GN, LZH; YB, QXY \\
\hline 3 & WK; LB, LZ; TM, GN, LZH; YB, QXY \\
\hline
\end{tabular}

(5-2)

\begin{tabular}{|c|c|}
\hline Level & Users (K-Plex) \\
\hline \hline 1 & WK, LB, LZ, LZH, TM, GN \\
\hline 2 & WK, LB, QXY \\
\hline 3 & WK, LB, YB \\
\hline 4 & WK, LZ, QXY \\
\hline 5 & WK, LZ, YB \\
\hline 6 & WK, QXY, LZH \\
\hline 7 & WK, QXY, TM \\
\hline 8 & WK, QXY, YB \\
\hline 9 & WK, QXY, GN \\
\hline 10 & WK, LZH, YB \\
\hline 11 & WK, TM, YB \\
\hline 12 & WK, YB, GN \\
\hline
\end{tabular}

Structural Hole is an important theory of Social Capital, and it is shown that people would get some advantages only because of their position in the network. The central node could reap some additional benefits in the network, as the diverse connections could provide them much more opportunities and useful intelligence [25]. When two points possess non-redundant path, we can be sure there is a structural hole between them. Meanwhile, an ideal network structure requires both clusters and structural holes [26]. In this part, we have performed some specialized Structural Hole measures.

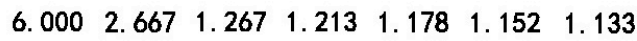

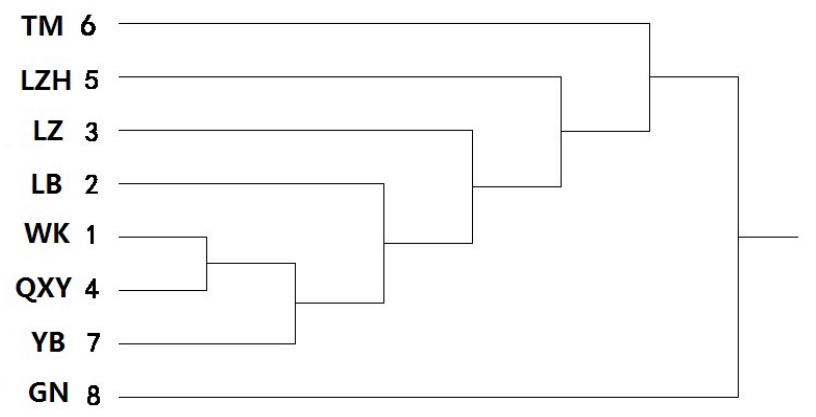

Fig. (5). K-Plex analysis of the Wechat user.

\subsection{Clustering Analysis}

Clustering is used to distinguish the objects into multiple groups that the ones in same cluster have higher similarity, but are very different to the other parts. Similarities and dissimilarities are assessed based on the data describing the objects. It is defined as "a statistical classification technique for determining whether the individuals of a population would fall into different groups by making quantitative comparisons of multiple characteristics" (Jain, 2009). Although the concept of N-Cliques is much clearer and easier for understanding, its vulnerability is very obvious. Once we move some nodes of a network, the structure would become very different [27]. In routine research, we often adopt K-Plex to improve the robustness. After gradually reducing the attribution values, we can get Table $\mathbf{5}$ as the result of the classification. This part of clustering analysis is based on the Hierarchical Clustering and Concor Partition Diagram.

Although the UCINET could only handle binary value in Hierarchical Clustering, the main information is still present in the results, and the dendrogram (Fig. 5) given as follows.

From the results, it can be seen that the users are more likely to be classified into one group, when the connections between them are analogous to others. YB and QXY are classmates in real life, both admitted in September 2014. And the others are students of the same supervisor. WK plays a relatively large role in this network, because he is across the two groups. That is what we call "Structure Hole". 


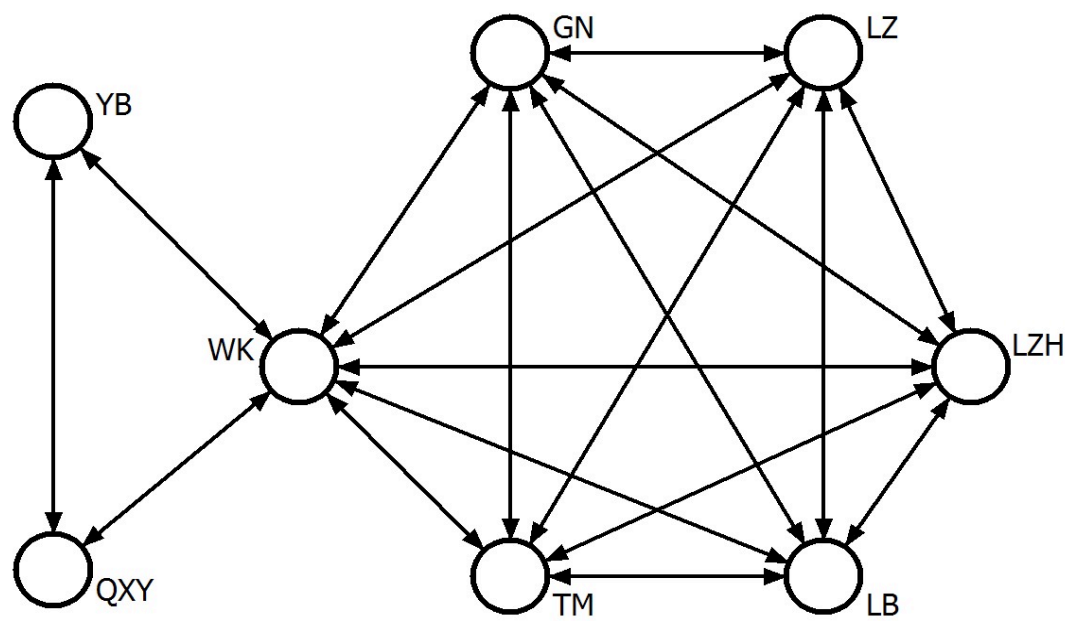

Fig. (6). Sociogram of the random chosen Wechat user.

We can understand the network easier and more intuitionally through the following Fig. (6).

\section{THE WECHAT INFORMATION TRANSMISSION TOPOLOGY}

After understanding the structure of these groups above, and combining it with characteristics analysis, we can summarize several topologies that exist in information transmission, mainly Point to Point Topologies, Mesh Topology, Star Topology, etc. As this paper is focused on information transmission topology, it is possible for the researchers to reveal these characteristics based on data from a random chosen user. A brief primary analysis of these topologies is given as follows [28].

\subsection{Point to Point Topology}

In some cases, the discussion among Wechat users is usually focused on one topic, which leads to the appearance of Point to Point Topology. This model is the most convenient way of information exchange, and it always contains only two points and the topics are specific that others cannot get involved in. In this mode, External-Internal Index is -1, which means information flow entirely takes place in the cohesion subgroup. Points in this pattern can completely control each other, and once any partner exits, it leads to the failure of the information interaction. Due to its simple structure and no issues in feedback, frequency, and many other aspects, Point to Point Topology is the most efficient mode. Almost every user, under the private chat, was included in this mode (Fig. 7).

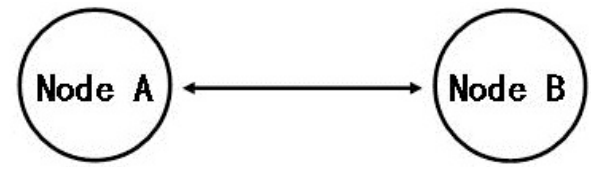

Fig. (7). Example of the Point to Point Topology.

\subsection{Mesh Topology}

In many cases, there are various basic views in discussions, which form several factions, but are still in the same group. There are two or more centers which more or less have some correlations. The individuals at this status may comment on different topics, while common interests really play a decisive role in this topology. The network density is much smaller, and the center points have relatively high Point Centrality, leading to a higher control of the others. The rest points in this network also have a higher Closeness Centrality, so they are easy to be controlled. In this model, members have greater equality, because no one could really hold the center position in this process of information transmission for a long time. The commonly used function in the software, Group Chat, is the best example of this topology (Fig. 8).

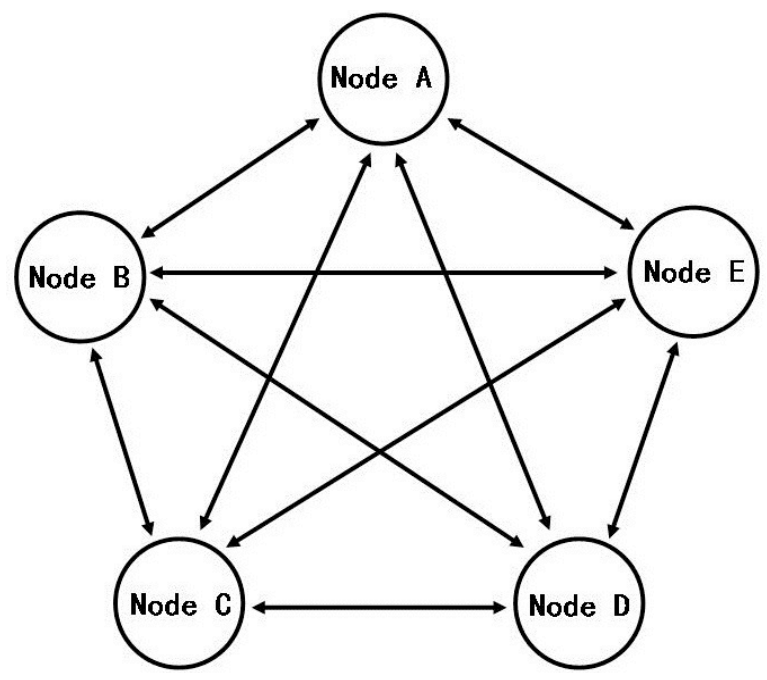

Fig. (8). Example of the Mesh Topology.

\subsection{Star Topology}

In this mode, a relatively stable center exists of the whole network. The approach of information flow is oneway, which means that the center releases the information and the others have to obtain it. In Wechat, the most direct instance is that you share some comments or photos in the Moments. In this case, other friends may just wait and see, that makes the information sender have a high Point Centrality. The structure of information flow in this mode is also shown as the Tree Topology. This topology is the best way for the information publisher to enhance his subjective willingness. It only depends on the stability of the center node at 


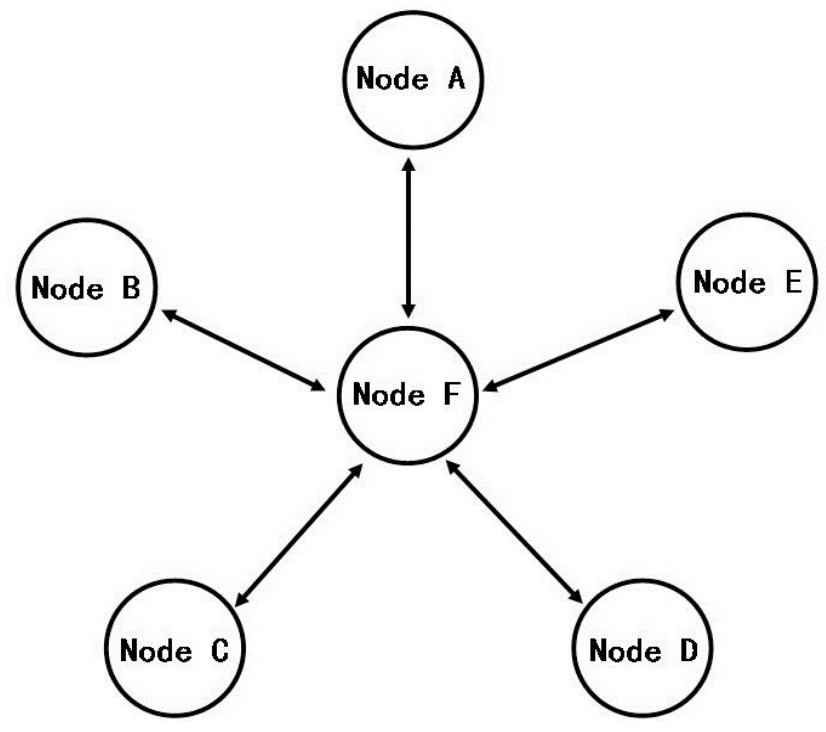

Fig. (9). Example of the Star Topology.

this status, whether such model can successfully complete the process of information transmission or central idea can be recognized by the others. It can be seen in the Sociogram that the User WK occupies such key role in the network. The topology can be abstracted in the following graph (Fig. 9).

\section{CONCLUSION}

(1) This study has briefly introduced the theories of Social Network Analysis at the beginning. And then, based on its own concept and methods, we have mainly obtained three kinds of information transmission topology that exist in the network of general Wechat user, such as the Point to Point Topology, Mesh Topology and Star Topology. Meanwhile, this paper has also provided some detailed resolutions about these models with the results of UCINET.

(2) Social Media is not only a channel of information transmission, but also a small online community. It has become an essential service that is provided to the participants by the internet company. With the rapid development of mobile internet, the future of Social Media not only relies on the efforts of users, but also depends on the management of the providers.

\section{ABOUT THE AUTHORS}

First Author Wang Kun, College of Information System and Management, National University of Defense Technology, Master Degree Candidate. The author's major is the Social Network Analysis, International Relations. 3 papers received by EI.

Second Author Sun Duoyong, College of Information System and Management, National University of Defense Technology, Professor, Ph.D.Supervisor. The author's major is National Security and Crisis Management.

\section{CONFLICT OF INTEREST}

The authors confirm that this article content has no conflict of interest.

\section{ACKNOWLEDGEMENTS}

UCINET is a social network analysis program developed by Professor Steve Borgatti, Martin Everett and Lin Freeman. This software is distributed by Analytic Technologies [29]. Our research is financially supported by the National Natural Science Foundation of China (Grant No.71473263) and the Specialized Research Fund for Doctoral Program of Higher Education of China (Grant No.20134307110020).

\section{REFERENCES}

[1] "WeChat". Available: http://en.wikipedia.org/wiki/WeChat\#cite note-48 [Accessed: Oct. 19, 2014].

[2] "Tencent Announces 2014 Second Quarter and Interim Results". http://tencent.com/en-us/content/ir/news/2014/attachments/20140813. pdf [Accessed: Oct. 19, 2014].

[3] "CIOTC". Available: http://www.ciotc.cn/a/Industry/wuxianchengshi/2013/0303/5758.html [Accessed: Oct. 19, 2014].

[4] "Micro Letter dated live showing subscriber growth, micro-chennal gaming has become a major force pulled". Available: http:// www.sfw.cn/xinwen/442082.html [Accessed: Oct. 19, 2014].

[5] Z.Z. Fang, "Basic concepts and methods of social network research," Journal of Huazhong University of Science and Technology (Social Science Edition), vol. 3, pp. 111-112, 2005.

[6] C. Prell, Social Network Analysis: History, Theory and Methodology, SAGE Publications, 2011.

[7] M. Emirbayer, and J. Goodwin, "Network analysis, culture and the problem of agency" American Journal of Sociology, vol. 99, no. 6, pp. 1411-1454, 1994.

[8] N. Memon, and D. L. Hicks, "Detecting Key Players in Terrorist Network: A Case Study of 9-11," In: The $3^{\text {rd }}$ International Conference on Availability, Reliability and Security, IEEE computer society, 2008.

[9] J. Liu, An Introduction to Social Network Analysis, Social Science Academic Press (China), 2004 (in Chinese).

[10] A. Bavelas, "A Mathematical Model for Group Structures," Human Organization, vol. 7, pp. 16-30, 1948.

[11] S. Burt Ronald, Structural holes: the Social Structure of Competition, Harvard University Press, 1992.

[12] J.D. Luo, Social Network Analysis $\left(2^{\text {nd }}\right.$ ed), Social Sciences Academic Press(China), 2010 (in Chinese)

[13] S. Wasserman, and K. Faust, Social Network Analysis: Methods and Applications, Cambridge University Press, New York and Cambridge, 1994.

[14] A. Galeotti, C. Ghiglino, and F. Squintani, "Strategic Information Transmission Networks," Journal of Economic Theory, vol. 148, pp. 1751-1769, 2013.

[15] A.L. Barabasi, and R. Albert, "Emergence of scaling in random networks," Science, vol. 286, pp. 509-512, 1999.

[16] M. Mitchell, Complexity: A Guided Tour, Oxford University Press, 2009.

[17] M. Newman, A.L. Barabasi, and D.J. Watts, The Structure and Dynamics of Networks, Princeton University Press, Princeton, NJ, 2006.

[18] D.J. Watts, and S.H. Strogatz, "Collective dynamics of 'smallworld' networks," Nature, vol. 393, pp. 440-442, 1998.

[19] "Six Degree: Comes in your time is up" Available: http://blog.karlbunyan.com/2009/06/24/six degrees-come-in-yourtime-is-up/ [Accessed: Oct. 19, 2014].

[20] "Six Degrees of Separation, Twitter Style," April 30, 2010. [Accessed: Oct. 19, 2014].

[21] "What is Social Networking" Available: http://www.whatissocial networking.com/ [Accessed: Oct. 19, 2014].

[22] J.P. Scott, Social Network Analysis: A Handbook (2 ${ }^{\text {nd }}$ ed), SAGE Publications, 2000.

[23] M. Bastian, S. Heymann, and M. Jacomy, "Gephi: an open source software for exploring and manipulating networks," In: The $3^{\text {rd }} I n$ ternational Conference on Weblogs and Social Media, May 2009, pp. 361-362.

[24] "WeChat". Available: https://wx.qq.com/. [Accessed: Oct. 19, 2014].

[25] R. Burt, "Structural Holes and Good Ideas," American Journal of Sociology, vol. 110, no. 2, p. 349, 2004 
[26] R. Burt, Structural Holes: The Social Structure of Competition, Harvard University Press, Cambridge, MA, 1992.

[27] S.B. Seidman, B.L. Foster, "A graph-theoretic generalization of the clique concept," Journal of Mathematical Sociology, vol. 6, pp. 139-154, 1978.
[28] "MediaChina". Available: http://academic.mediachina.net/article. php?id=6398 [Accessed: Oct. 19, 2014].

[29] "UCINET Software". Available: http://www.analytictech.com/ ucinet/ [Accessed: Oct. 19, 2014].

(C) Kun and Duoyong; Licensee Bentham Open.

This is an open access article licensed under the terms of the Creative Commons Attribution Non-Commercial License (http://creativecommons.org/licenses/by-nc/4.0/) which permits unrestricted, non-commercial use, distribution and reproduction in any medium, provided the work is properly cited. 